\title{
Faktor-Faktor Yang Mempengaruhi Keterlambatan Pengembalian Berkas Rekam Medis Rawat Jalan Di UPT Rumah Sakit Khusus Paru Tahun 2019
}

\author{
Ali Sabela Hasibuan \\ Program Studi D-III Perekam Medis dan Informasi Kesehatan, Universitas Imelda Medan
}

\begin{tabular}{l} 
Article Info \\
\hline Article history: \\
Received Feb24, 2020 \\
Revised Feb26, 2020 \\
Accepted Feb28, 2020 \\
\hline
\end{tabular}

\section{Keywords:}

Returning Medical Records delay in returning files Patients

\begin{abstract}
ABSTRAK
Medical record unit is an important part in a hospital, because medical records contain activities ranging from receiving patients, recording, managing patient medical record data, storing and returning medical record files. In addition, medical record units must be able to service requests for information relating with medical record data quickly, precisely and accurately at the time required. One of the factors that influence the speed of service delivery to patients is the timeliness of returning medical record files to the medical record unit. inpatient medical record at UPT Medan Special Lung Hospital. This type of research uses quantitative descriptive research methods. Population in the study of officers relating to filling medical records in the Special Lung RSR totaling 15 people, with the sampling technique is the total sampling which amounted to 15 people. Brilliant The results of research that have been conducted by researchers that the factors that most influence the delay are carrying out established procedures and incompleteness in filling medical record documents both in the patient's identity and accuracy in filling out the diagnosis also affect the delay in returning the medical record file and carry out the procedures specified in the hospital returns the medical record file for a maximum of $1 \times 24$ hours, if the return of the medical record file is delayed it will greatly affect the assembling, analysis, coding, indixing, filling and reporting.
\end{abstract}

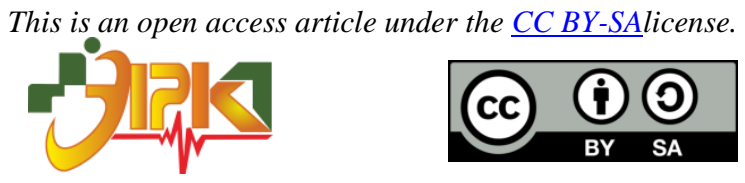

\section{Corresponding Author:}

Ali Sabela Hasibuan,

Program Studi D-III Perekam Medis dan Informasi Kesehatan,

Universitas Imelda Medan,

Jl. Bilal No. 52 Kelurahan Pulo Brayan Darat I Kecamatan Medan Timur, Medan - Sumatera Utara.

Email: alisabelahasibuan@gmail.com

\section{PENDAHULUAN}

Rekam medis adalah berkas yang berisi catatan dan dokumen tentang identitas pesien dan pelayanan lain kepada pasien di sarana pelayanan kesehatan (Hatta, 2008). Menurut Permenkes RI No.269/Menkes/Per/III/2008 tentang rekam medis, menjelaskan bahwa rekam medis adalah berkas yang berisi catatan dan dokumen tentang identitas pasien, pemeriksaan, pengobatan, tindakan dan pelayanan lain yang telah diberikan kepada pasien.

Unit rekam medis merupakan bagian yang penting dalam suatu rumah sakit, karena rekam medis memuat kegiatan mulai dari penerimaan pasien, pencatatan, pengelolaan data 
rekam medis pasien, penyimpanan dan pengembalian berkas rekam medis. Selain itu, unit rekam medis harus mampu melayani permintaan informasi yang berkaitan dengan data rekam medis dengan cepat, tepat dan akurat pada waktu yang dibutuhkan. Salah satu faktor yang berpengaruh dalam kecepatan pemberian pelayanan kepada pasien adalah ketepatan waktu pengembalian berkas rekam medis ke unit rekam medis. Dalam pelaksanaannya kegiatan ini didukung oleh petugas rekam medis, yaitu petugas yang bertanggung jawab dalam pembuatan kebijakan prosedur pelaksanaan kebijakan prosedur pelaksanaan rekam medis terkait menjaga mutu pelayanan rekam medis.

Rekam medis dapat mendukung peningkatan mutu pelayanan kesehatan, yaitu dengan melakukan pendokumentasian secara cepat dan tepat. Dengan ini tercipta suatu pelayanan yang cepat dan tepat dimana pasien tidak menunggu terlalu lama untuk berobat. Dan dengan pendokumentasian berkas rekam medis yang dilakukan secara cepat dan tepat pula maka akan diperoleh data yang berguna untuk perencanaan dan pengawasan dalam memberikan pelayanan kesehatan yang berkesinambungan terhadap pasien. Apabila dalam pelaksanaan pengisian berkas rekam medis tak dilakukan secara cepat dan tepat, maka akan berpengaruh dalam proses pengembalian berkas rekam medis ke unit rekam medis.

Dalam pelayanan di rumah sakit yang standar, dokter membuat catatan mengenai berbagai informasi mengenai pasien dalam satu berkas yang dikenal sebagai Rekam Medis atau Medical Record. Berkas ini merupakan satu berkas yang memiliki arti penting bagi pasien, dokter, tenaga kesehatan atau rumah sakit (Depkes, 2006).

Pelayanan rekam medis bukan pelayanan dalam bentuk pengobatan, tetapi merupakan bukti pelayanan, financial, aspek hukum dan ilmu pengetahuan. Peran rekam medis sangat dibutuhkan untuk mengelola bahan bukti pelayanan kesehatan dengan aman, nyaman, efisien, dan rahasia. Rekam medis merupakan bukti tertulis tentang proses pelayanan yang diberikan oleh dokter dan tenaga kesehatan lainnya kepada pasien dalam rangka penyembuhan pasien. Penyelenggaraan rekam medis proses kegiatan yang dimulai dari saat diterimanya pasien di rumah sakit, diteruskan dengan kegiatan pencatatan data medis pasien selama pasien itu mendapatkan pelayanan medik di rumah sakit dan dilanjutkan dengan penanganan berkas rekam medis yang meliputi penyelenggaraan penyimpanan dan pengeluaran berkas dari tempat penyimpanan (Depkes, 2006).

Setelah pasien mendapatkan pelayanan medis kemudian pasien pulang maka berkas rekam medis sebaiknya dikembalikan lagi ke ruang penyimpanan supaya berkas tersebut tidak hilang atau tercecer sehingga kerahasiaannya tetap terjaga.Penyelenggaraan rekam medis pada suatu sarana pelayanan kesehatan merupakan salah satu indikator mutu pelayanan pada institusi tersebut. Pengembalian berkas rekam medis akan berpengaruh pada proses pemberian pelayanan kepada pasien (Depkes, 2006).

Pengembalian berkas rekam medis ke unit rekam medis menjadi terlambat atau tidak tepat waktu.Pengembalian berkas rekam medis dengan tepat waktu merupakan salah satu usaha yang dapat dilakukan untuk menciptakan menejemen rekam medis yang berkualitas. Pengembalian berkas rekam medis dengan tepat waktu sangat diperlukan untuk menejemen rekam medis karena ketepatan waktu pengembalian berpengaruh terhadap proses pengolahan data rekam medis. Keterlambatan terhadap pengembalian berkas rekam medis menyebabkan keterlambatan pula terhadap pengolahan data rekam medis yang akan berpengaruh pada pengembalian kebijakan, keputusan menejemen, serta penyampaian informasi kepada pasien. Apabila hal ini terjadi berkelanjutan maka akan sangat mempengaruhi pengambilan keputusan yang akan merugikan bagi pihak rumah sakit maupun pihak pasien. Bagi rumah sakit akan mempengaruhi informasi yang disampaikan kepeda pemimpin tidak tersaji secara tepat waktu yang berguna untuk pengambilan keputusan serta kebijaksanaan manajemen secara efektif dan hal ini mengahambat pembuatan pelaporan oleh petugas. Bagi pihak pasien akan mempengaruhi pengobatan selanjutnya dan terlambat dalam mengetahui informasi tentang kesehatan dirinya atas 
pelayanan yang telah diberikan. Penelitian sebelumnya yang berkaitan dengan penyebab keterlambatan waktu pengembalian berkas rekam medis menyatakan Faktor penyebab keterlambatan waktu pengembalian berkas rekam medis rawat inap yaitu disebabkan oleh dokter yang terlambat mengisi kelengkapan berkas rekam medis, belum adanya petugas khusus pengembalian berkas rekam medis rawat inap, serta jarak Instalasi rawat inap ke Instalasi rekam medis yang cukup jauh sehingga mengakibatkan keterlambatan pengembalian berkas rekam medis rawat inap ke Instalasi rekam medis (Purba, 2019).

Berdasarkan survei awal yang dilakukan di UPT Rumah Sakit Khusus Paru Medan masih sering terjadi keterlambatan dalam pengembalian berkas rekam medis. Keterlambatan pengembalian berkas rekam medis tersebut mengakibatkan keterlambatan pula dalam pelayanan pasien.

Menurut prosedur pengembalian berkas rekam medis di Rumah Sakit UPT Khusus Paru, berkas rekam medis harus dilengkai pengisiannya dan dikembalikan tepat waktu paling lama 1x24 jam setelah pasien pulang. Hal ini dimaksudkan agar petugas rekam medis siap menyediakan berkas rekam medis jika sewaktu-waktu diperlukan. Selain itu, pengembalian rekam medis yang tepat waktu dapat berpengaruh terhadap pengolahan data dan informasi yang dibutuhkan oleh rumah sakit.

Adanya keterlambatan pengembalian berkas rekam medis akan menghambat kegiatan selanjutnya, yaitu kegiatan coding, indexing, serta kemungkinan menyebabkan hilang atau rusaknya berkas rekam medis. Apabila hal tersebut terjadi secara berkelanjutan maka akan menghambat penyampaian informasi kepada pemimpin rumah sakit untuk pengambilan keputusan. Selain itu juga dapat menghambat kegiatan pelayanan berikutnya jika sewaktuwaktu dibutuhkan untuk keperluan hukum.

\section{METODE PENELITIAN}

A. Jenis Penelitian

Jenis penelitian ini menggunakan metode penelitian deskriptif. Menurut Notoatmodjo, 2012, metode penelitian deskriptif adalah suatu metode penelitian yang dilakukan dengan tujuan utama untuk membuat gambaran atau deskripsi tentang suatu keadaan secara objektif. Penelitian ini dilaksanakan pada bulan Oktober sampai Desember Tahun 2019. Tempat Penelitan dilakukan di UPT Rumah Sakit Khusus Paru Medan.

B. Populasi

Populasi adalah keseluruhan subjek penelitian yang menjadi populasi dalam penelitian petugas kesehatan yang berhubungan dengan pengisian DRM di UPT Rumah Sakit Khusus Paru Medan.

C. Sampel

Menurut Notoatmodjo, 2012, sampel adalah bagian dari objek yang diteliti jumlah dan karakteristiknya dan mewakili seluruh populasi. Sebagai petugas perawat berjumlah 15 orang.

D. Teknik Sampeling

Adapun teknik sampling yang digunakan oleh peneliti adalah random sampling.

E. Teknik Pengumpulan Data

Metode Angket, angket adalah suatu cara pengumpulan data atau suatu penelitian mengenai suatu masalah yang umumnya banyak menyangkut kepentingan umum (orang banyak).

F. Defenisi Operasional

Untuk membatasi ruang lingkup atau pengertian variabel-variabel yang diamati atau diteliti, perlu sekali variabel-variabel tersebut diberi batasan atau defenisi operasional (Notoadmojo, 2012). 
1. Faktor keterlambatan adalah alasan yang mempengaruhi keterlambatan pengembalian dan kelengkapan pengisian rekam medis.

2. Prosedur dan kebijakan pengembalian berkas rekam medis

3. Kelengkapan dalam pengembalian pengisian dokumen rekam medis diruang

G. Instrumen

Instrumen yang digunakan adalah kuesioner. Kuesioner adalah daftar pertanyaan yang sudah tersusun dengan baik, sudah matang, dimana responden tinggal memberikan jawaban atau dengan memberikan tanda-tanda tertentu (Notoatmodjo, 2012).

\section{HASIL DAN PEMBAHASAN}

\subsection{Hasil}

Tabel 1. Data Umum Distribusi Frekuensi Responden

\begin{tabular}{ccc}
\hline Kategori & jumlah & $\%$ \\
\hline A. Jenis Kelamin & & $67 \%$ \\
\hline Laki-Laki & 10 & $33 \%$ \\
\hline Perempuan & 5 & $100 \%$ \\
\hline Total & 15 & $100 \%$ \\
\hline B. Umur (Tahun) & & $0 \%$ \\
\hline $21-30$ & 15 & $100 \%$ \\
\hline $31-40$ & 0 & $67 \%$ \\
\hline Total & 15 & $33 \%$ \\
\hline C. Pendidikan & & $100 \%$ \\
\hline D-III & 10 & $67 \%$ \\
\hline S-1 & 5 & $33 \%$ \\
\hline Total & 15 & $100 \%$ \\
\hline D. Lama Kerja & & \\
\hline 1-5 Tahun & 10 & \\
\hline 6-10 Tahun & 5 & \\
\hline Total & 15 & \\
\hline
\end{tabular}

Berdasarkan tabel 1 menunjukan distribusi frekuensi berdasarkan karakteristik responden tentang pengembalian berkas rekam medis, diperoleh gambaran hasil peneliti tentang jenis kelamin responden, umur responden, pendidikan responden, dan lama bekerja responden.

Tabel 2. Distribusi Frekuensi Pengetahuan Perawat Dalam Pengembalian Berkas Rekam Medis

\begin{tabular}{cccc}
\hline No & Pengetahuan & Frekuensi & $\%$ \\
\hline 1. & Baik & 9 & $60 \%$ \\
\hline 2. & Kurang & 6 & $40 \%$ \\
\hline & Total & 15 & $100 \%$ \\
\hline
\end{tabular}

Berdasarkan tabel 2 Pengetahuan perawat dalam pengembalian berkas rekam medis yang berpengetahuan baik sebanyak 9 orang (60\%), dan yang berpengetahuan kurang baik sebanyak 6 orang $(40 \%)$.

Tabel 3. Distribusi Frekuensi Prosedur dan Kebijakan Dalam Pengembalian Berkas Rekam Medis

\begin{tabular}{cccc}
\hline No & Prosedur dan Kebijakan & Frekuensi & $\%$ \\
\hline 1. & Baik & 5 & $33,3 \%$ \\
\hline 2. & Kurang & 10 & $66,6 \%$ \\
\hline
\end{tabular}




Total $15 \quad 100 \%$

Berdasarkan tabel 3 prosedur dan kebijakan dalam pengembalian berkas rekam medis yang berdasarkan baik sebanyak 5 orang $(33,3 \%)$, dan yang kurang sebanyak 10 orang $(66,6 \%)$.

Tabel 4. Distribusi Frekuensi Kelengkapan Dalam Pengembalian Berkas Rekam Medis

\begin{tabular}{llll}
\hline NO. & Kelengkapan Pengembalian & Frekuensi & \% \\
\hline 1. & Baik & 6 & $40 \%$ \\
\hline 2. & Tidak Baik & 9 & $60 \%$ \\
\hline Total & $\mathbf{1 5}$ & $\mathbf{1 0 0 \%}$
\end{tabular}

Berdasarkan tabel 4 kelengkapan dalam pengembalian berkas rekam medis yang berdasarkan baik sebanyak 6 orang (40\%), dan yang berdasarkan tidak baik sebanyak 9 orang $(60 \%)$.

\subsection{Pembahasan}

Sesuai hasil penelitian yang telah dilakukan di UPT Rumah Sakit Khusus Paru Medan Tahun 2019 ada beberapa hal yang diperoleh menjadi faktor keterlambatan pengembalian berkas rekam medis rawat jalan yaitu sebagai berikut :

\section{Pengetahuan}

Berdasarkan tabel 2 pengetahuan perawat dalam pengembalian berkas rekam medis yang berpesngetahuan baik sebanyak 9 orang (60\%), dan yang berpengetahuan kurang baik sebanyak 6 orang (40\%).

Menurut asumsi peneliti, perawat yang berpengetahuan baik lebih tinggi dari pada perawat yang berpengetahuan kurang baik. Berdasarkan pengetahuan ada kaitannya dengan pengalaman atau lama kerja dan pendidikan. Sebagai petugas tenaga kesehatan harus memiliki pengetahuan yang lebih baik akan pentingnya pengisian diagnosis dan ketepatan pengembalian berkas rekam medis.

\section{Prosedur dan kebijakan pengembalian berkas rekam medis}

Berdasarkan tabel 3 prosedur dan kebijakan dalam pengembalian berkas rekam medis yang berdasarkan baik 5 orang $(33,3 \%)$, dan yang kurang 10 orang $(66,6 \%)$.

Menurut asumsi peneliti, pelaksanaan prosedur dan kebijakan yang kurang baik lebih banyak dari pada yang baik. Seharusnya prosedur yang telah ditetapkan harus dijalankan oleh pihak rumah sakit. Setiap rumah sakit memiliki prosedur tentang pengembalian berkas rekam medis bahwa setiap berkas rekam medis harus sudah dikembalikan ke unit rekam medis 1x24 jam setelah pasien keluar dari rumah sakit.

\section{Kelengkapan}

Berdasarkan tabel 4 kelengkapan pengembalian berkas rekam medis yang berdasarkan baik 6 orang (40\%), dan yang tidak baik 9 orang (60\%).

Menurut asumsi peneliti, ketidaklengkapan pengembalian berkas rekam medis lebih banyak dari pada yang lengkap. Hal tersebut seharusnya petugas lebih memperhatikan pengisian dari berkas rekam medis agar tidak terjadi dokumen ataupun data yang tidak lengkap dari pasien tersebut.

Rekam medis seharusnya dibuat segera dan dilengkapi setelah pasien menerima pelayanan. Pembuatan rekam medis sebagaimana dilaksanakan melalui pencatatan dan pendokumentasian hasil pemeriksaan pengobatan, tindakan dan pelayanan lain yang telah 
diberikan kepada pasien, dan setiap pencatatan dalam rekam medis harus di bubuhi nama, waktu dan tanda tangan yang memberikan pelayanan kesehatan secara langsung.

Kelengkapan berkas rekam medis sangat penting ataupun pengisian berkas juga sangat berpengaruh dalam pengembalian berkas rekam medis baik identitas pasien ataupun diagnosis juga harus diperhatikan.

\section{KESIMPULAN}

Ketidaklengkapan berkas rekam medis yang sangat banyak menjadi penyebab keterlambatan dalam pengembalian berkas rekam medis baik dalam pengisian diagnosa ataupun dokumen rekam medis

\section{REFERENCES}

Depertemen Kesehatan. 2009. Tugas Dan Fungsi Rumah Sakit. Jakarta.

Dirjen Yanmed. 2006. Tujuan Rekam Medis dan Kegunaan Rekam medis. Jakarta: Rineka Cipta.

Gemala, R, Hatta, 2011. Pendoman Manajemen Informasi Kesehatan di Sarana Pelayanan Kesehatan. Jakarta: Penerbit Universitas Indonesia.

Menkes RI. 2007. Kepmenkes Nomor 377 Tahun 2007Tentang Standar Profesi Perekam Medis dan Informasi Kesehatan. Jakarta: Indonesia

Mubarak. 2011. Faktor yang mempengaruhi pengetahuan, Jakarta: Indonesia.

Notoatmodjo. 2012. Metode penelitian Kesehatan. Jakarta: Rineka Cipta.

Permenkes RI No 340. 2010. Undang-undang No. 36 Tentang Klasifikasi Rumah Sakit. Jakarta: Indonesia.

Purba, E. (2019). Faktor Penyebab Keterlambatan Waktu Pengembalian Berkas Rekam Medis Rawat Inap Di Rs Estomihi Medan Tahun 2019. JURNAL ILMIAH PEREKAM DAN INFORMASI KESEHATAN IMELDA, 4(2), 626-636. http://jurnal.uimedan.ac.id/index.php/JIPIKI/article/view/86/88.

SK Men PAN. 2008. Perekam Medis dan Informasi Kesehatan. Yogyakarta: Graha Ilmu.

Sugiono. 2009. Keterlambatan Pengembalian Berkas Rekam medis. Yogyakarta

\section{BIOGRAPHIES OF AUTHORS}

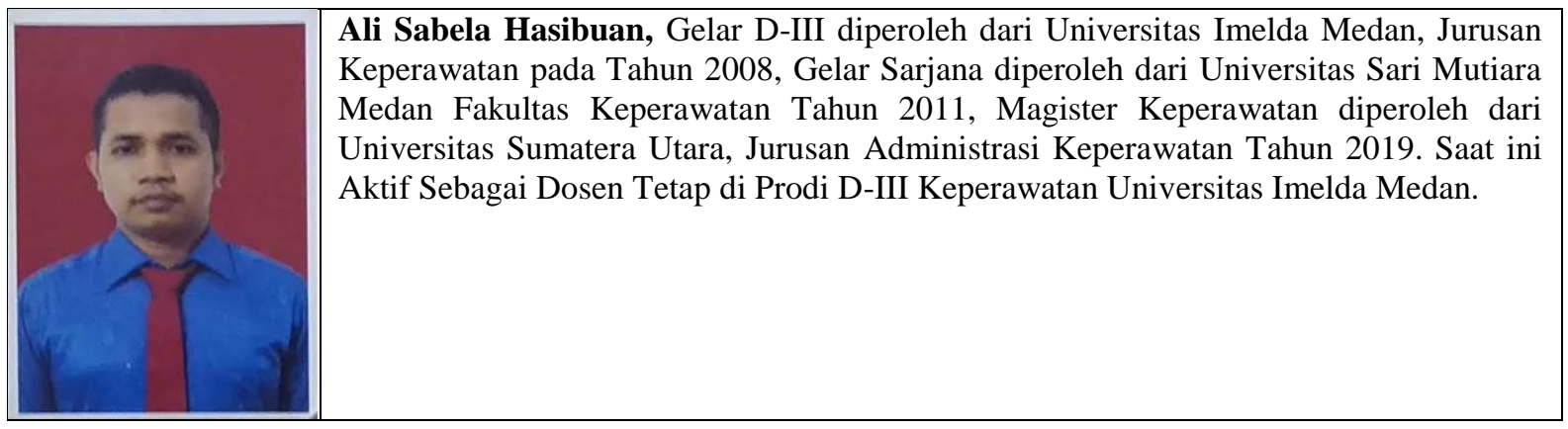

